\title{
Biobanking for Interdisciplinary Clinical Research
}

\author{
P.H.J.Riegman W.N.M. Dinjens J.W. Oosterhuis \\ Department of Pathology, Josephine Nefkens Institute, Erasmus MC, Rotterdam, The Netherlands
}

\author{
Key Words \\ Bio-repositories in medical research • Tissue banking • \\ Bio-repository networks
}

\begin{abstract}
Biobanking nowadays is mostly strongly determined by the specific aims of a research group in charge of the biobank, determining their own standards for the collection and annotation of samples. Often a long period is needed to build up the sample and data collections, especially when longterm follow-up data is required. Such collections need a long-term dedication and proper funding. Neglecting either sample number or annotation can result in insignificant or poor results. However, outcome of translational research does not only depend on the sample quality. In many cases it can also be improved to start the experimental design within a multidisciplinary team composed of clinicians including pathologists, molecular biologists, statisticians, bioinformaticians and tissue resource managers. Such a team, capable of careful evaluation of the numbers needed and which or what part of the samples are to be included, could help in obtaining far better results. Many lines of clinical research could benefit more efficiently from the wealth of information stored in well-preserved disease-oriented tissue sample collections with the proper annotations, when the infrastructure around biobanks and new collection build-up is well organized, standardized and streamlined. Future medical research will refine its scientific questions, demanding even further refinement of corresponding clinical information. In addition, larger sample collections are needed to
\end{abstract}

study for instance multifactorial diseases. Today, the samples are collected for tomorrow, therefore, improvement is needed now in standardization, automated enrichment of annotations from hospital information systems and disease registries, insight in overlapping collections of different forms of tissue banking and cooperation in national and international networks.

Copyright $\odot 2007$ S. Karger AG, Basel

\section{Introduction}

The combination of biobanking, high throughput research together with bioinformatics and the unraveling of the human genome and transcriptome have proven to be a powerful approach in biomedical research. It opens up many opportunities in the field of diagnostics, predictive factors, biomarkers, pharmacogenetics, drug discovery and understanding of disease mechanisms, thereby giving the potential to have a major impact on prevention, diagnosis, prognosis, prediction and treatment of human diseases. To fully exploit this revolution in the combat of human disease it is vital to have access to large quantities of human tissue samples of high quality, ideally both diseased and unaffected fresh unfixed tissue samples from patients and unaffected tissues from healthy control individuals [1-5]. There are many varieties of tissue banks. Differences are found in infrastructure, scale, material, procedures, storage and annotation, which largely depend on the goal for which the tissue bank was created.

\section{KARGER}

Fax +41613061234

E-Mail karger@karger.ch

www.karger.com
(C) 2007 S. Karger AG, Basel

$1015-2008 / 07 / 0744-0239 \$ 23.50 / 0$

Accessible online at:

www.karger.com/pat
P.H.J. Riegman, $\mathrm{PhD}$

Department of Pathology, Josephine Nefkens Institute, Be 235b

Erasmus Medical Center, PO Box 2040

NL-3000 CA Rotterdam (The Netherlands)

Tel. +31 10408 8421, Fax +31 10408 9487, E-Mail p.riegman@erasmusmc.nl 


\section{Varieties of Biobanks}

Many different approaches exist to exploit tissue samples in medical science; hence many different forms of biorepositories for medical research exist even within one institute. Large infrastructural differences are seen between populations based on disease-oriented bio-repositories. Population biobanks collect material from a large group of people to identify characteristics recognizing a disease in people developing a disease, whereas disease-oriented repositories concentrate on collecting diseased materials $[1,6-8]$. However, disease oriented biobanks can be seen as a part of population biobanking, as they nowadays support research on controlled groups of people.

Disease-oriented repositories can be split up into project-driven and systematic ones $[1,8]$. Project-driven collections are disease- or organ-based. Specialized research groups performing dedicated research on these organs or diseases collect the residual samples and most often also actively collect the corresponding follow-up data. To set up such a scientifically valuable collection of populationbased or disease-driven repositories takes many years of investment.

The systematic collection, often found at academic pathology departments, is very similar to the project-driven collection, but is not limited by only one or a series of similar organ types or disease. Available residual tissues, which could form an interesting study object, are collected and stored without the need of a specific aim at the time of collection. This way, valuable time can be saved to start up medical research based on tissue sample collections with sufficient numbers of high quality. Data is also collected, but less detailed as in project-driven collections where the complete follow-up is added. This laborious task can also be done at a time when it is clear what data is specifically needed for the research project the samples will be part of.

\section{The Role of Academic Hospitals}

Academic hospitals play a pivotal role in establishing the collections, a role they have performed so far to answer their needs. However, it is clear that even the large academic centers cannot live up to the future demands on their own. They will need to implement standardizations to live up to the quality needed to join multicenter research, and in addition collect tissues not directly needed for their own research, but also those which can be of importance for other research centers. In exchange they might benefit from obtaining opportunities to take part or cooperate in research not performed at the institute or at least demand compensation in costs endured when collecting and storing the samples.

It takes many different clinical disciplines to work together to establish a good collection. Nowadays, it is often the role of the tissue resource manager of a certain tissue bank somewhere in the organization to coordinate all the different research wishes. It is better to organize an institute wide tissue bank, having an overview of all collected samples showing also overlap in collections. Actual sample collection will be concentrated at the departments of pathology, surgery (and all disciplines therein), oncology and clinical chemistry. However, these departments need feedback on what samples are worthwhile to collect from each other and the clinical research departments, like epidemiology, oncology, pathology, clinical genetics, etc. Ideally, the collection process could benefit largely by an addition to the hospital information systems of a central tissue bank administration and tracking system of all collected samples, also enabling the different disciplines to see whether samples of a certain disease need to be collected. It would also be worthwhile to know for instance if a patient is entered in a large-scale clinical trial on which translational research will be performed, the patient belongs to a population under study or it concerns a patient also known from a local cohort study, etc. Permitting the pathology department, in case there is enough residual tissue available, to prepare a frozen sample and an extra formalin-fixed paraffin-embedded block from residual tissues, which can later be used without problems in multicenter studies during the study collection procedure. The clinical chemistry department can store any residual blood when a sample has been stored elsewhere at departments of surgery or pathology. The samples can be earmarked for that particular study. The central system should offer scientists the possibility to search for clinical data on sample identity without revealing the donor identity by using a sample code number. In case of multicenter studies it should in addition have an option to export these data only under sample identity or even completely anonymized to other facilities that need the data for analysis. These data can vary depending on the needs of that particular study however and can even be completed with radiology scans and pathology images of macros and histology supported by virtual microscopy [9]. Last but not least, for regional collections of samples an input of external data is required consisting of a flexible web-based system on which forms with programmable questions 
and preset choices for standardized data input will allow easy data input for regional volunteers.

The pathology department plays a central role in the collection of disease-oriented tissues because here many surgical specimens are brought in for further diagnosis. Since the diagnostic process may never be hindered by collecting tissue for experimental use, the pathologist responsible for the diagnosis is the person of choice to determine what part of the specimen is not needed for the diagnostic process and can be seen as residual and be stored for further scientific purposes [5]. Residual tissues not needed for further diagnosis at pathology can be frozen at the surgery department under the responsibility of the surgeon. The pathologist is in later stages instrumental in the selection process for the appropriate tissues to be used in the experiment and judging the expected tissue characteristics in every sample planned to be used.

The department of clinical chemistry can play a prominent role in the collection of blood/serum/buffy coat samples from patients suspected from certain pre-chosen disease groups or when a population or cohort study is launched. The residual specimen from the diagnostic procedures can be stored for further use. Centralized storage facilities can be recommended to lower storage costs, due to inefficient storage or even inefficient systems with uncoordinated maintenance, alarm and backup systems. However, even at large institutes after many years of collecting it still proves to be difficult to supply high numbers of extensively defined or rare types of tissue specimens.

\section{Networks}

Uniting tissue banks in networks can be useful in case the research requires high numbers of extensively defined or rare types of samples. Precious time can be saved when starting up a study. Ideally, such a network can be realized on a national level, uniting the academic centers in a virtual tissue bank within one country. In case of disease-driven repositories, the collection of academic centers can be optimized by a regional network consisting of peripheral hospitals for collecting samples of cases rarely treated in the academic centers with centralized storage at the academic centers.

Exchanging tissue within one country is not hampered by differences in law. To overcome deficiencies at the national level, the academic centers can be organized in larger international networks of virtual tissue banks like for instance TuBaFrost. This network was created in a European framework 5 project for frozen tumor samples [9-14] (www.tubafrost.org). It is still active after funding, because it is fully integrated in the OECI (Organisation of European Cancer Institutes). This European cancer organization aims to establish comprehensive cancer centers to improve quality of care and innovation of which tissue banking in an international network forms part. The period after funding needs to be considered as an integral part of a business plan of temporarily funded biobank projects.

International tissue-banking initiatives have been financed temporarily in diverse areas, some more successful than others. In the future, there is a need of larger infrastructure to even enable studies of multifactorial diseases in an efficient way. Such studies are in need of many more than a few hundred well-defined samples and can easily increase to thousands. In parallel, there will also be an increasing demand for more accurate and standardized sample annotation. It would therefore be mutually beneficial to unite the successful initiatives again into cooperative and communicative networks opening up new challenges for future medical research. Involvement of disease registries could be extremely helpful to enlarge the quality of annotation and in turn the epidemiological studies can benefit from the availability of samples to study molecular correlations with epidemiological findings. In addition, cohort studies and population banks could benefit from the availability of overlapping samples derived from the same donor in the disease-oriented repositories, whereas the disease-oriented studies would be able to study samples or the collected data of samples before the disease was recognized. Data exchange on a local regional level between epidemiology, disease registries, and the different forms of bio-repositories with a secured patient/person identity relation operating in the back of a database application for anonymized data retrieval can result in a much more accurate and useful annotation of the samples. Disclosure of such information for instance in validation of a potential progression predicting biomarker of which progression takes about a decade would be extremely valuable to add to the data of already collected samples. Ideally, next to the hospital information on the actual disease it could be very helpful to add the whole disease and treatment history of the patient, ideally to be tapped from the new or to develop national electronic patient file or record systems without revealing the identity of the patient to the scientist. In addition, demographic, lifestyle and socioeconomic data could also be very worthwhile including. Disclosure of these data when needed in an anonymized way 
and in compliance with the privacy rules should be made easy to obtain for medical scientists. Enhancement of the outcome of translational research by direct coupling of this information to the bioinformatics systems analyzing the experiment could reveal very surprising and unexpected correlations.

International cooperation between tissue banks is one of the major topics in international biobanking platforms, e.g. 'The Marble Arch International Working Group on Biobanking for Biomedical Research' - a group of biobank leaders from different countries over the world working on harmonization of global tissue banking, and 'ISBER' - The International Society for Biological and Environmental Repositories. Two major subjects are inseparable from this topic: standardization of sample collection/storage procedures complete with quality control program to avoid intrinsic bias in multicenter studies [2] and standardization of annotation. A project designing infrastructure for a network in the European situation, thus depending of volunteering tissue banks and based on temporary funding, standardization and a quality control program, has to be as non-invasive as possible. The minimal investments needed during implementation must not involve any unnecessary costs or measures. Such standardization has been developed for frozen tissue giving strict demands in some areas and many choices in those areas where sample quality is not harmed, leading to equal high sample quality [11].

The design of a network must be a cooperative design [4], demanding a slight change of attitude of the collectors in the approach of collecting tissues. Despite the fact that cooperation in multicenter research projects on the bases of tissue collections between institutes is nowadays seen as instrumental, the own interests in the collection can severely jeopardize such cooperation. Large differences in scientific value of specific samples between institutes can be used however to even optimize this situation with a set of appropriate access rules. In addition, incentives to share not only input in the form of samples but also output like resulting data and publications are of major importance. Especially in case a network is dependent on volunteers the rules of access and use become even crucial to the integrity of the network. During TuBaFrost development it became clear that a network could only function when sample custodianship stays with the original collector [13]. These access rules provide normal access to the samples for the collecting institute to issue for local use like before entering the network. So the sample is not given away to a large organization, taking top-down decisions on to what project proposals and to whom samples are issued. Local institutes can use their own authorization method for external tissue requests. Leaving the decision to the local institutes will clearly give a better representation of the scientific value of a requested collection to the institute. This is directly expressed in their willingness to join or reject a request.

In large-scale international clinical trials the ideal situation for translational research would be to have tissue samples frozen, paraffin-embedded and blood samples from all included patients. The size of the group, the inclusion criteria of the trial, the information collected on the patients and in time follow-up, result in a collection with again a wealth of information waiting to be extracted. The power in this collection is within the group of included patients itself and more importantly, data resulting from translational research can even be of direct use for trial enrichment when determination of characteristics of responders versus non-responders is pursued. Translational research needs to be taken up already in the phase of trial design, to become part of the trial description and therefore need careful consideration in advance. Tissue banking also needs to be considered as well as standardization of the complete collecting and storage procedure. Custodianship is still a matter of concern. Again the question is who decides what translational research is to be performed on the collected samples. Suggestions to give custodianship temporarily to the trial management for matters of convenience already meets opposition, but is for now considered the best option. This of course under the condition the sample is to be returned immediately without question when asked for by the institute of origin. Intellectual property rights can have the same adverse effect when treated wrong.

The consequence of networks and multicenter translational research for local tissue banks is that standardization of procedures together with a quality assurance program, the data needed for annotations and the proper consent procedure need to be implemented. Guidelines for standard operating procedures or best practices have been developed for tissue banking; however, the descriptions often do not anticipate international cooperation or only focus on the highest possible scientific value or stay limited to a particular form of tissue banking [15].

\section{Legal Issues}

To enable multicenter studies on international levels it is important to also tackle from the start the legal issues involved in international tissue exchange. Privacy and 
consent procedures both need to be considered when exchanging tissues from one country to another. Consent procedures must include the possibility for international multicenter studies from the start of the collection. Although there is high variety of laws in every country, the TuBaFrost consortium has provided a code of conduct for residual tissue, respecting not only the laws of the country of origin, but is strongly embedded within European law [12]. It is a coordinating rule respecting the laws in the country of origin: If tissue may be legitimately used for certain research in the country where it was collected and under whose jurisdiction the patient falls, it may also be used for such research in the country where it is sent to in the context of a scientific program even if that other country has other regulations in force for residual tissue research collected from patients under their jurisdiction. The minimum demand for consent is an opt-out system. International trials need to consider the appropriate procedure during trial design to enable translational research in compliance to the European directive on trials. Extra tissue not falling under residual tissue generally always need informed consent, however opinions and legislation differ enormously on residual tissues.

From studies done on patients giving or refusing consent it is well known that about only $1 \%$ of the patients refuse on the basis of principle not having their tissues used [16]. Therefore, the informed consent procedure for this group is considered to be rather extreme for the 99\% that have no problems with donating residual tissues even for commercial medical research purposes. An opt-out system could very well serve the $1 \%$ without spending scarce medical research money obtaining consent [17].

\section{Improvement of Translational Research}

The collection of human material is situated at the beginning of the chain of translational research. This chain follows an important principle, cited many times concerning tissue banking, 'garbage in, garbage out'. It implies that when sourced bio-repositories consist of samples, which are badly collected, processed, stored or annotated, the end result of a complete experiment based on these samples can be of no better quality, despite the sophisticated techniques or analysis method chosen to perform the research.

To avoid, however, any further disappointment over the outcome it is important to be aware that the whole chain indeed starts with the collection of samples and the needed clinical data up to the final analyses, where every following link of the chain needs to be of equal strength. Careful planning is very important where the appropriate scientific tool or technique is selected, the tissue must be carefully judged on containing the expected tissue in the right proportion (no mixtures due to heterogeneity), statistics are needed in advance to plan the amount of samples needed to get a significant end result. This means a multidisciplinary team is needed, ideally consisting of at least a molecular biologist, a statistician, a surgeon or clinical specialist involved in the treatment, a pathologist, a bioinformatician and a tissue resource manager. A misconception often encountered is the failure to recognize the underlying histology of the tissue sample used in a research project. Awareness of tissue heterogeneity or existence of areas with unaffected, inflammatory infiltration, different or even pre-stages and the occurrence of sometimes many diverging subgroups within the disease group (e.g. lung cancer is a disease group consisting of many diverging subtypes with completely different characteristics) is key to success. The involvement of a pathologist within the research program particularly for histology review and advice on the aspects of the tissue sample can make the difference between failure and success. Therefore, we would like to suggest changing the 'garbage in, garbage out' principle in tissue research in 'garbage coming in from any link of the translational research chain will result in garbage out'.

Although it seems a huge investment to make for sound translational research on human samples, the power of the end result is too valuable for medical research to neglect. It is a task we need to undertake to more efficiently face the combat of human disease. It must, however, not be forgotten that these multidisciplinary tasks can only be fully exploited thanks to the generous donors, who are rightfully expecting progress to be made in medical care due to their donations. Therefore, sharing data and tissues for good research need to be considered as an obligation for those involved in decisions on access of samples to the donors. They cannot consider these patient materials as items that can be owned solely for personal success. The tissue resource manager as well as all others involved in the decisions on the access of tissues in the bio-repositories are merely the custodians of the samples, acting in the best interest of the donors. 


\section{References}

-1 Oosterhuis JW, Coebergh JW, van Veen EB: Tumour banks: well-guarded treasures in the interest of patients. Nat Rev Cancer 2003; 3:73-77.

$>2$ Knox K, Kerr DJ: Establishing a national tissue bank for surgically harvested cancer tissue. Br J Surg 2004;91:134-136.

-3 Teodorovic I, Therasse P, Spatz A, Isabelle M, Oosterhuis W: Human tissue research: EORTC recommendations on its practical consequences. Eur J Cancer 2003;39:22562263.

4 Morente MM: Tumour banks and oncological research. Rev Oncol 2003;5:63-64.

5 Grizzle WE, Woodruff KH, Trainer TD: The pathologist's role in the use of human tissues in research-legal, ethical, and other issues. Arch Pathol Lab Med 1996;120:909-912.

$\checkmark 6$ Goodman MT, Hernandez BY, Hewitt S, et al: Tissues from population-based cancer registries: a novel approach to increasing research potential. Hum Pathol 2005;36:812820.

7 Hirtzlin I, Dubreuil C, Preaubert N, Duchier J, Jansen B, Simon J, Lobato De Faria P, Perez-Lezaun A, Visser B, Williams GD, Cambon-Thomsen A, Eurogenbank Consortium: An empirical survey on biobanking of human genetic material and data in six EU countries. Eur J Hum Genet 2003;11:475488.

$>8$ Cambon-Thomsen A: The social and ethical issues of post-genomic human biobanks. Nat Rev Genet 2004;5:866-873.

$>9$ Teodorovic I, Isabelle M, Carbone A, Passioukov A, Lejeune S, Jamine D, Therasse P, Gloghini A, Dinjens WN, Lam KH, Oomen MH, Spatz A, Ratcliffe C, Knox K, Mager R, Kerr D, Pezzella F, van Damme B, van de Vijver M, van Boven $\mathrm{H}$, Morente MM, Alonso S, Kerjaschki D, Pammer J, Lopez-Guerrero JA, Llombart Bosch A, van Veen EB, Oosterhuis JW, Riegman PH: TuBaFrost 6: virtual microscopy in virtual tumor banking. Eur J Cancer 2006;42:3110-3116. DOI: 10.1016/ j.ejca. 2006.04 .033
10 Riegman PH, Dinjens WN, Oomen MH, Spatz A, Ratcliffe C, Knox K, Mager R, Kerr D, Pezzella F, van Damme B, van de Vijver $\mathrm{M}$, van Boven $\mathrm{H}$, Morente MM, Alonso S, Kerjaschki D, Pammer J, Lopez-Guerrero JA, Llombart Bosch A, Carbone A, Gloghini A, Teodorovic I, Isabelle M, Jamine D, Passioukov A, Lejeune $S$, Therasse $\mathrm{P}$, van Veen EB, Lam KH, Oosterhuis JW: TuBaFrost 1: uniting local frozen tumor banks into a European network: an overview. Eur J Cancer 2006;42:2678-2683.

11 Morente MM, Mager R, Alonso S, Pezzella F, Spatz A, Knox K, Kerr D, Dinjens WN, Oosterhuis JW, Lam KH, Oomen $\mathrm{MH}$, van Damme B, van de Vijver M, van Boven $H$, Kerjaschki D, Pammer J, Lopez-Guerrero JA, Llombart Bosch A, Carbone A, Gloghini A, Teodorovic I, Isabelle M, Passioukov A, Lejeune S, Therasse P, van Veen EB, Ratcliffe C, Riegman PH: TuBaFrost 2: standardising tissue collection and quality control procedures for a European virtual frozen tissue bank network. Eur J Cancer 2006;42:26842691.

12 Van Veen EB, Riegman PH, Dinjens WN, Lam KH, Oomen MH, Spatz A, Mager R, Ratcliffe C, Knox K, Kerr D, van Damme B, van de Vijver M, van Boven H, Morente MM, Alonso S, Kerjaschki D, Pammer J, LopezGuerrero JA, Llombart Bosch A, Carbone A, Gloghini A, Teodorovic I, Isabelle M, Passioukov A, Lejeune S, Therasse P, Oosterhuis JW: TuBaFrost 3: Regulatory and ethical issues on the exchange of residual tissue for research across Europe. Eur J Cancer 2006; 42:2914-1423. DOI: 10.1016/j.ejca.2006.04. 028
13 Lopez-Guerrero JA, Riegman PH, Oosterhuis JW, Lam KH, Oomen MH, Spatz A, Ratcliffe C, Knox K, Mager R, Kerr D, Pezzella $F$, van Damme B, van de Vijver M, van Boven $\mathrm{H}$, Morente MM, Alonso S, Kerjaschki D, Pammer J, Carbone A, Gloghini A, Teodorovic I, Isabelle $M$, Passioukov $A$, Lejeune $S$, Therasse P, van Veen EB, Dinjens WN, Llombart-Bosch A: TuBaFrost 4: access rules and incentives for a European Tissue Bank. Eur J Cancer 2006;42:2924-299. DOI: 10.1016/ j.ejca.2006.04.030

14 Isabelle $\mathrm{M}$, Teodorovic I, Morente MM, Jamine D, Passioukov A, Lejeune S, Therasse $\mathrm{P}$, Dinjens WN, Oosterhuis JW, Lam KH, Oomen MH, Spatz A, Ratcliffe C, Knox K, Mager R, Kerr D, Pezzella F, van de Vijver M, van Boven H, Alonso S, Kerjaschki D, Pammer J, Lopez-Guerrero JA, Llombart Bosch A, Carbone A, Gloghini A, van Veen EB, van Damme B, Riegman PH: TuBaFrost 5: multifunctional central database application for a European Tumor Bank. Eur J Cancer 2006; 42:3103-3109. DOI:10.1016/j.ejca.2006.04. 032

15 Hede K: New biorepository guidelines raise concerns. J Natl Cancer Inst 2006;98:952954

16 Jack AL, Womack C: Why surgical patients do not donate tissue for commercial research: review of records. BMJ 2003;327: 262

17 Grobbee DE, van Veen E-B: Code of proper secondary use of human tissue in the Netherlands. Federation of Biomedical Scientific Societies (FMWV), 2003, available in English at www.fmwv.nl 